\title{
Contos baldios
}

\author{
[ Wasteland tales
}

\section{Márcio Marciano}

RESUMO - A seção Criação tem por objetivo publicar textos e materiais inéditos de escritores e/ou artistas, fotógrafos, desenhistas, além de documentos inéditos encontrados no Arquivo do IEB-USP. Neste número, são publicados três Contos baldios, de Márcio Marciano. Dramaturgo e encenador, Marciano fundou a Companhia do Latão, em São Paulo, ${ }^{2}$ e o Coletivo de Teatro Alfenim, em João Pessoa ${ }^{3}$. Atualmente é consultor da Academia Paraibana de Cinema. Nas palavras do crítico José Antonio Pasta (20I7, p. 22), seu trabalho artístico "tem o vezo de procurar resolver os problemas, não ao aliviálos, obviando o que neles é obstáculo, mas, ao contrário, incrementando a sua dificuldade, extremando-a, até que ela passe no seu outro".

PALAVRAS-CHAVE - Márcio Marciano; contos; literatura brasileira; literatura brasileira contemporânea. ABSTRACT - The
Creation section has the objective of publish unpublished texts and materials by writers and/or artists, photographers, designers, as well as unpublished documents found in the USP IEB Archive. In this issue, three Contos baldios (Wasteland tales), by Márcio Marciano, are published. A playwright and director, Marciano founded Companhia do Latão, in São Paulo city, and Coletivo de Teatro Alfenim, in João Pessoa. He is currently a consultant at the Academia Paraibana de Cinema. For the critic José Antonio Pasta (20I7, p. 22), Marciano's artistic work “has a habit of trying to solve the problems, not by relieving them, obviating what is an obstacle in them, but, on the contrary, increasing your difficulty, intensifying it, until it passes into your other". KEYWORDS • Márcio Marciano; tales; brazilian literature; contemporary brazilian literature

Recebido em 2I de junho de $202 \mathrm{I}$

Aprovado em 28 de agosto de $202 \mathrm{I}$

MARCIANO Márcio. Contos baldios. Revista do Instituto de Estudos Brasileiros, Brasil, n. 80, p. I87I94, dez. 202I.

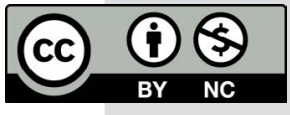

DOI: https://doi.org/Io.II606/issn.23I6-90IX.vIi8opI87-I94

I Academia Paraibana de Cinema (APC, João Pessoa, Paraíba, Brasil).

2 Sobre a Companhia do Latão, consultar COSTA (2008), CARVALHO (2009) e MATSUNAGA (2013).

3 Sobre o Coletivo de Teatro Alfenim, consultar EFREM FILHO (20I5), FERRAZ JÚNIOR (20I6) e FERREIRA (20I8). 


\section{Roupa de molho}

Antes de se despedir, como sempre fazia ao final do expediente, recomendou à patroa que vigiasse as crianças no fim de semana. Melhor que não entrassem na lavanderia, deixara em bacias a roupa de molho e não gostava que fosse remexida com banhos de bonecas ou mergulhos de dinossauros. Contra o argumento de que o tecido se esgarçava tanto tempo ensaboado, opunha artimanhas do ofício: roupa é como gente, carece de molho, é no descanso que se percebe a virtude do trabalho. Quanto à resiliência das tramas, tinha lá seus macetes: a quantidade precisa de água sanitária para as brancas, de sabão em pó para as de cor; a esfrega uma a uma nas mãos destras quase a dispensar a máquina; o zelo estudado de quem cuida como quem possui. As colegas do condomínio arengavam - mistura de despeito e desprezo -, tamanho cuidado com a roupa "dos outros" cheirava a ofensa. Não se ofendia. Aprendera a guardar distância das miudezas, seja da inveja subalterna, seja do amor-próprio ferido. Já que precisava do trabalho, que fosse. Sem esperança maior do que contas pagas e os de casa assistidos. Arrimo que era de família sem eira, aprendeu a andar no meio fio da existência, com um pé no limbo e outro na lama. Entre si e os patrões, fincara a bandeirola da decência. Não pedia nem lastimava, mas também não cedia o que era de direito. Que pagassem em dia. Quando não, amarrava a cara nas fuças do demônio. A patroa na horinha mesma desconfiava de algum desarranjo no trato da palavra empenhada. Sem carimbo em carteira, tinha lá suas razões de arrelia. A confiança é como bolha de sabão, dizia: brilha e flutua, mas só enquanto não estoura. A rotina de muitos anos não mudara com a chegada dos filhos. Se antes recomendava que o patrão não ultrapassasse os domínios da lavanderia, agora era preciso incluir as crianças. Nas demais dependências da casa, resignara-se ao estoicismo do ofício a tal ponto que era capaz de não se enojar de nenhuma imundície. A técnica de apenas respirar com a boca e a convicção de que neste mundo ninguém é melhor que ninguém a persuadiam de que a dignidade do trabalho bem-feito supera as mesquinharias. Chegava a ter satisfação de si mesma nas ocasiões em que era preciso controlar o engulho para apagar os resquícios da porcaria alheia. Quando esta se resumia às exalações cotidianas, obstinava-se ao laborioso trabalho da faxina. Na lavanderia, contudo, às voltas com a roupa que jamais cogitara usar um dia, sentia-se recompensada das demais labutas. O perfume do sabão em pó, o jorro da água abundante, um certo frescor que a fazia lembrar-se da infância quando acompanhava a mãe à beira do rio, retemperavam-lhe o ânimo. Naquela dependência da casa, desfrutava o refúgio da autonomia.

Quando chegou, às sete da manhã - era segunda-feira, dia em que passava a maior parte do tempo lavando as roupas da semana -, notou que algo inesperado mudara a rotina da casa. Um bilhete escrito às pressas, deixado sobre a mesa da cozinha, dava em frase lacônica a terrível notícia: durante a madrugada a patroa sofrera um ataque cardíaco e não resistira. O garrancho desleixado do patrão ordenava arranjar as coisas, recolher o lixo e fechar a casa. Ligasse depois para receber as contas e entregar a chave. Assim, sem explicações desnecessárias. Puxou a cadeira 
mais próxima, sentou-se levando a mão direita à boca, irrefletida, como quem tenta encobrir o pasmo. Releu o bilhete. Olhou em torno, parecendo procurar nos azulejos a decifração de um mistério. Lá se fora parte de sua vida, como a água suja do molho. Dobrou o papel do bilhete, mecanicamente, guardou-o na bolsa. Restava cumprir a ordem, como sempre fizera durante aquela longa convivência entre fantasmas. Não fosse a notícia, faria o de sempre, a reinar sozinha na casa até a chegada da família, no final da tarde. Tratou da limpeza como quem lava um defunto. Os gestos eram os mesmos, mas algo na casa decompunha-se. Um retrato da patroa sobre o piano pareceu acenar-lhe do além. Sentiu calafrios, fez um sinal da cruz. Por um instante pensou que quase era dia do pagamento. Terminada a tarefa dos cômodos, restava a roupa de molho. A do patrão e das crianças, jogou na máquina. Duas batidas antes do enxágue, sem amaciante, penduradas no varal do teto, indiferentes. A da patroa, não. Uma a uma repassou-as na esfrega cuidadosa, mãos hábeis como a acariciar o tecido. Depois as torceu, quem sabe senão para espremer das tramas os últimos vestígios de vida. Arranjadas no varal de armar, ao lado do tanque, as roupas pareciam desbotar-se diante de seus olhos, sem destinação. Enxugou as mãos, deu um breve suspiro. Refletiu se devia deixar um recado. Olhou mais uma vez para as roupas no varal. Cismou ter ouvido a patroa. Recolheu o lixo, saiu e trancou a casa. Antes de partir, jogou a chave por baixo da porta. 


\section{A sopeira dos trocados}

O velho utensílio de louça pertencia à família havia cinco gerações. A sopeira, com sua fina camada de esmalte, estava trincada. Sua superfície convertera-se num sutil rendilhado de nervuras. Em seu bojo, a pintura esmaecida pelo tempo representava o arbitrário encontro de duas cenouras com um lagostim. Era um objeto delicado, de uma beleza incongruente em contraste com os móveis e demais utensílios da moderna cozinha. Colocado num vão do armário que ficava à entrada, servia de enfeite e homenagem à memória de um tempo de posses, em que mesmo a mais singela sopa requeria ares de nobreza. Hoje, não ia mais à mesa. Prestava-se como depósito aos cacarecos de utilidade duvidosa: pilhas em desuso, chaves extraviadas, grampos de cabelo, tampas de caneta, clipes e cartões de visitas. Porém, sua mais distinta utilidade era servir de caixa para trocados. Em seu interior se depositavam cédulas miúdas e moedas que cobriam as despesas domésticas de pequeno porte: gás, galões de água, a condução da diarista e eventuais gastos de última hora. O patrão se encarregava de prover a sopeira para a semana. Às segundas-feiras, ao sair para o trabalho, depositava no interior da louça uma nota de cem, que por pouco tempo reinava entre os trocados remanescentes da semana anterior. Esse hábito - e a lição que encerrava - aprendera com o pai: era preciso que houvesse confiança dentro de casa. A empregada atual, filha da empregada anterior e neta da primeira agregada, tinha de ter seu naco de autonomia, uma vez que a ela cabia a direção dos serviços domésticos. Sendo assim, Antônia - era esse seu nome - administrava os trocados da sopeira como um gerente qualificado. Apesar das viravoltas da economia, com sua dança inflacionária, o patrão não perdia de vista a quantia que nunca se acumulava: nem muito nem pouco, havia sempre um trocado de reserva, de modo que assim acreditava abrandar a incumbência da empregada. Raras vezes, Antônia precisava alertar a patroa sobre possíveis quebras de caixa. Quando se anunciavam despesas extras, além do orçamento ordinário, a patroa se encarregava de mediar a transação, reportando ao marido o gasto fora da rotina. Desta vez, havia a visita para o conserto do ar-condicionado, a matrícula da natação do filho adolescente e a lembrancinha de Antônia, que faria aniversário no próximo domingo. Informado com antecedência, o patrão pusera na sopeira cinco notas de cem. Embora descontente com a acumulação do dispêndio, tinha satisfação em ver como fluía essa espécie de circulação do capital doméstico. A semana transcorreu sem maiores distúrbios de rotina, apesar da sujeira e dos ruídos do técnico, que ocupou por uma tarde inteira o quarto do casal e a lavanderia, onde limpou as grades removidas do aparelho. Afora o intruso, prevalecia a paz doméstica, embora o filho adolescente andasse de ovo virado, batendo portas, ouvindo música em alto volume, bradando interjeições hormonais em favor da liberdade do indivíduo. Antônia gostava do garoto, de quem trocara as fraldas, mas que agora a tratava com indiferença e certa grosseria. O que fazer? Sabia que o menino tinha bom caráter e que aquela fase passaria logo. Só não gostava quando ele metia a mão na sopeira e ela era obrigada a se virar para que os pais não desconfiassem dos pequenos furtos. Terminado o serviço, o técnico passou o recibo. A patroa com enxaqueca pediu que Antônia despachasse o sujeito. Instantes depois, o porteiro interfonava para avisar que o boy da natação estava na portaria. Feitas as contas, a sopeira sofreu grande desfalque: lá se foram quatro notas gordas. 
Mesmo assim, a louça manteve o moral da tropa restante, composta de cédulas de baixa patente e algumas moedas rasas. Restava ainda um general, a derradeira nota de cem. Acontece que o filho adolescente tinha urgências. Aproveitando a enxaqueca da mãe e a ausência de Antônia, que abandonara a cozinha para pôr o quarto do casal em ordem enquanto a mãe repousava na sala de cortinas cerradas, o garoto subtraiu a nota de cem, e mais outra de menor valia. Skate debaixo do braço, saiu batendo a porta da cozinha, sem dizer a que horas voltava. O caso passaria despercebido, não fosse o aniversário. Dia seguinte, como fazia todos os sábados, Antônia preparou-se para ir à feira exclusiva do condomínio. Nada além de três bancas especialmente montadas com peixes frescos e frutas da estação. Com o excedente da semana, a empregada se orgulhava de conseguir verdadeiras pechinchas. Porém, ao levantar fundos na caixa de louça, deu pela falta da nota de cem. Imediatamente, pensou no garoto e na desculpa que haveria de inventar, enquanto abria a porta de serviço. A patroa, restabelecida dos achaques, estava pronta para a caminhada habitual pelas alamedas do condomínio. Aproveitaria o momento para pegar a lembrancinha, um jogo americano de crochê que havia encomendado à companheira do porteiro. Pagaria com a nota de cem restante. Como de costume, foi direto à sopeira em busca do dinheiro e surpreendeu-se com vê-la desprovida de notas graúdas. Observou que os trocados remanescentes dariam para a despesa, mas se negou a raspar o tacho. Ponderou que a sovinice do marido não havia deixado a quantia suficiente. Esse contratempo deixou-a levemente irritada. Desistiu de sair. Voltou a cerrar as cortinas da sala e se esparramou no sofá, ofendida. Ao voltar, Antônia notou o mal-estar da patroa. Nessas ocasiões, o melhor a fazer era restringir-se aos domínios da cozinha e cuidar do almoço, à espera da tempestade que se formava e que cairia inevitavelmente. Dito e feito. Mal o patrão adentrou a sala, chegando da rua, Antônia pôde ouvir o espatifar de um copo contra a parede. Em seguida, as cortinas foram abertas com estardalhaço, e ela pôde distinguir, entre rumores e reclamações, ofensas entrecortadas por choro e arrastar de móveis. Essas habituais tormentas domésticas iam e vinham como chuvas de verão. Sua tarefa era esperar a calmaria e, então, recolher os cacos e pôr-se ao lado da patroa, num mutismo solidário enquanto o patrão se refugiava em algum cômodo do apartamento. Porém, naquela manhã, a patroa estava ligeiramente mais sensível e o patrão, ligeiramente mais bêbado. Após o espalhafato da primeira onda emotiva, a empregada redobrou a atenção. A voz pastosa do patrão pedia calma, a voz chorosa da patroa, acolhimento. Passara a noite sem notícias do marido e do filho adolescente, sentia-se sozinha e abandonada. Em meio aos pedidos de desculpa, ouviu seu nome, a notícia de seu aniversário no domingo e algo sobre toalhinhas de crochê. Em seguida a frase cristalina: "sempre some alguma coisa”. Um amargo sentimento de pudor lhe fez retrair-se e, ato contínuo, apoiou-se no armário em frente à sopeira. Um torpor envergonhado lhe deu cócegas na garganta. Da sala vinham murmúrios de apaziguamento. A empregada respirou fundo, engoliu seco e, num gesto mecânico, empurrou suavemente a sopeira até o limite do móvel, deixando-a despenhar-se. Ouviu-se o estalo da louça numa infinidade de estilhaços. No chão, em meio aos cacos, moedas, grampos, chaves, uma caixa de fósforos. Os patrões, ocupados, nem se deram conta. Antônia retirou um palito da caixa. Também ela mantinha um hábito que era uma lição. Acendeu o fósforo e desejou a si mesma um feliz aniversário. 


\section{Solidariedade}

Amanhecia. A vizinha reconheceu as batidas na madeira, espécie de senha para as agruras do dia a dia. Abriu a porta. As crianças precipitaram-se adentro, acabrunhadas de sono, trêmulas de medo. Cumpriam mais uma vez o enredo de aninhar-se ao pé da amiga quando o pai chegava bêbado da rua. A mãe agradeceu e foi-se embora, já cantava o galo no terreiro do cortiço. Precisava pegar o trem do subúrbio. Se Deus permitisse e Nossa Senhora auxiliasse, apanharia a cria ao final da tarde, depois do serviço. O companheiro jazia na cama, fora de combate depois do porre, a ira aplacada na liça com a mulher. Não molestaria ninguém, arrependido que ficava após pelejas como aquela, de causas evidentes e secretos motivos. Dormiria o dia todo na tentativa de curar o embrulho do estômago, os coices do remorso. Na casa da vizinha, as filhas ficavam como coisinhas guardadas. Enquanto sacolejava nos trilhos, pensou no quanto a vida podia não ter sido tão besta. Arranjara-se com aquele homem a quem deu as duas filhas, não por amor ou desejo, mas por hábito de sonhar um companheiro de vez em quando. Alguém que risse quando ria e que se aninhasse com ela. Enquanto o homem esteve no emprego de vigia noturno, tudo era como Deus manda. Quando ele chegava ao cortiço pela manhã, depois de uma noite de trabalho, ela já tinha saído com as crianças. Deixava-as na creche particular, já que a pública nunca tinha vagas, depois seguia para o trabalho. Os dois salários somados, as contas em dia, as crianças assistidas, tudo parecia encaixe de brinquedo até o dia em que a mola do destempero saltou pra fora do mecanismo: o companheiro foi demitido por justa causa. Pretextou defesa da honra ao socar o gerente de produção quando este reclamou corpo mole no batente. Sentiu-se humilhado. Mas que ela não se alarmasse, em poucos dias, tinha certeza, estaria de novo empregado. O tempo passou e o emprego não veio. As crianças saíram da creche, o aluguel atrasou, precisou fazer gambiarra na luz e um gato no encanamento do vizinho. "Tudo é provisório", dizia. Quando saía atrás de emprego, passava o dia na rua. Voltava tarde da noite, bêbado e de mãos vazias. Ela corria para chegar antes dele. Pegava as crianças na vizinha, dava o de comer e punha para dormir. Ficava à espera da refrega. Vinha nesse desvalimento havia três meses. "Tudo é provisório", como ele dizia. Quanto ao propósito das pancadas, não sabia o que pensar. Sempre fora amoroso com ela e com as filhas. Culpava a falta de dinheiro e certo amor-próprio exagerado. Por ser ele franzino, a agressão não passava de alguns palavrões e um ou outro safanão, que ela esgrimia e revidava. Por fim, exaustos e desmoralizados pela própria indigência, arriavam na cama. Em poucos instantes ele dormia, alternando soluços e impropérios desconexos. Ela refletia vigilante até cair pelas tabelas. No dia seguinte, a vizinha, que sempre ouvia o escarcéu, alertava. Um homem assim em casa é um perigo. Melhor dar queixa na delegacia. "Tudo é provisório", respondia à vizinha, arremedando o companheiro. Porém, naquela manhã, durante o trajeto entre o cortiço e a casa da patroa, não pôde se desvencilhar do conselho que mais parecia um agouro. Entrou no apartamento pela porta de serviço atinando largar o companheiro e carregar as meninas para o amparo da família no interior. Ao entrar na cozinha, o susto pendurou-lhe a decisão nas grimpas da cachola. Na lajota fria, escanchada, a patroa, de camisola, desgrenhava-se. Sobre a mesa, desordem de copos e guimbas. O caso era 
de pancada, muito sua conhecida. Um som de musiquinha vinha da sala, coisa de frufrus no violão, melodia que lhe soava como dobre de finados. Teve pena da coitada, assim, desleixada de amor e vício. Mas apesar, solidarizava: era caso de polícia, assim como o seu, porém diferente na dose da desgraça. Apesar de a imagem parecer coisa de novela, a dor não era de mentirinha. Sentiu pena. A moça de habituais palavras secas e muitas ordens desaguava-se num lamento sem decoro. Para certificar-se de que estavam sozinhas, deu uma geral nos cômodos, a ver se não encontrava o autor das bordoadas. Desligou o som. Depois, cuidou para que a moça se recompusesse. Amparou-a até o sofá da sala, deu-lhe goles de água com açúcar. Olho inchado, boca esbeiçada, mãozinhas trêmulas, soluços, lágrimas, cheiro de cigarro e bebida. Feito passarinho de asa quebrada, a moça arrulhava desatinos. Sugeriu chamar ajuda, ela recusou. Quis telefonar para a família, a moça impediu. Tentou consolá-la com a religião, a moça ofendeu-se. Então, pôs-lhe uma compressa no olho manchado, e a moça agradeceu. Deu-lhe os comprimidos, como ela ordenou. Trouxe travesseiros e lençol, a moça fez que sim. Perguntou se podia abrir as janelas, achou melhor não. Quis saber se podia ligar a máquina de lavar, a moça protestou. Aninhada no sofá, pediu para ficar só. Ela perguntou se devia começar a faxina. A moça pediu que fosse embora. "Não quer mesmo que chame alguém?" A moça virou para a parede. "Minha diária?" A patroa não respondeu. Por instantes, ficou ali, contemplando o animalzinho. "Tudo é provisório", pensou. Vendo que a patroa se abismava, foi à cata da carteira. Juntou as notas. Não inteirava a diária. Pegou o que tinha e saiu.

\section{SOBRE O AUTOR}

MÁRCIO MARCIANO é dramaturgo e encenador. Fundou a Companhia do Latão (São Paulo/SP) e o Coletivo de Teatro Alfenim (João Pessoa/PB). É coautor do livro Companhia do Latão 7 peças, lançado em 2008 pela editora Cosac Naify. Atuou como crítico teatral da revista Bravo! de 2002 a 2004. Com o Coletivo de Teatro Alfenim, escreveu Quebra-Quilos (2007), Milagre Brasileiro (2010), Histórias de Sem Réis (2010), O Deus da Fortuna (20II), Brevidades (20I2), Memórias de um Cão (20I5), Helenas (20I7) e Desertores (20I9). Atualmente é consultor da Academia Paraibana de Cinema, trabalhando na criação de roteiros audiovisuais para fins de difusão em mídias sociais. coelhomarciano@gmail.com https://orcid.org/0000-000I-677I-2596 


\section{REFERÊNCIAS}

CARVALHO, Sérgio de (Org.). Introdução ao teatro dialético: experimentos da Companhia do Latão. São Paulo: Expressão Popular/ Companhia do Latão, 2009.

COSTA, Iná Camargo. “O nome do jogo”. In: CARVALHO, Sérgio de; MARCIANO, Márcio. Companhia do Latão 7 peças. São Paulo: Cosac Naify, 2008, p. I5-29.

EFREM FILHO, Roberto. "Lâminas de Corte: sobre três estratégias para o encontro com o 'humano"'. Revista do Instituto de Estudos Brasileiros. São Paulo, n. 60, 20I5, p. I52-I70. Disponível em: http://dx.doi. org/Io.II606/issn.23I6-90IX.voi6opI52-I70. Acesso em: I5 out. 202I.

FERRAZ JÚNIOR, Expedito. “Memórias de um cão: o humanitismo de Machado de Assis transposto para a linguagem dramática”. Machado Assis em linha. São Paulo, n. I9, 20I6. Disponível em: https://doi. org/I0.I590/I983-682I20I69I96. Acesso em: I5 out. 202I.

FERREIRA, Mayra de Brito. Sonoridades da cena: a expressão musical no teatro épico do Coletivo de Teatro Alfenim (PB). I47 f. Dissertação (Mestrado em Música). Centro de Comunicação, Turismo e Artes, Universidade Federal da Paraíba, 2018.

MATSUNAGA, Priscila Saemi. Trabalho do Latão. 228 f. Tese (Doutorado em Literatura comparada). Faculdade de Letras, Universidade Federal do Rio de Janeiro, 2013.

PASTA, José Antonio. “Dialética do Alfenim - nota crítica e teórica”. In: CABRAL, Adriano; MARCIANO, Márcio; COELHO, Paula. Memórias de um cão: caderno de Apontamentos. João Pessoa: Coletivo de Teatro Alfenim, 20I7, p. 2I-29. 